\title{
Development and Characterisation of Kainth Fruit Beverage Formulations: Nutritional Composition, Analysis, and Stability Study during Storage
}

\author{
Om Prakash ${ }^{1}$, Attar Singh Chauhan ${ }^{1}$, Ashok Kumar Maurya ${ }^{2}$, Vithal Balavant Kudachikar ${ }^{1, *}$ \\ ${ }^{1}$ Department of Fruit and Vegetable Technology, Academy of Scientific and Innovative Research (AcSIR), CSIR-Central Food \\ Technological Research Institute, Mysuru, South-Central Karnataka state, India. \\ ${ }^{2}$ National Dope Testing Laboratory, New Delhi-110003, India.
}

\begin{abstract}
How to cite this paper: Om Prakash, Attar Singh Chauhan, Ashok Kumar Maurya, Vithal Balavant Kudachikar. (2021) Development and Characterisation of Kainth Fruit Beverage Formulations: Nutritional Composition, Analysis, and Stability Study during Storage. International Journal of Food Science and Agriculture, 5(4), 704-716.

DOI: $10.26855 /$ ijfsa.2021.12.019

Received: October 21, 2021

Accepted: November 16, 2021

Published: December 9, 2021

*Corresponding author: Vithal Balavant Kudachikar, Department of Fruit and Vegetable Technology, Academy of Scientific and Innovative Research (AcSIR), CSIR-Central Food Technological Research Institute, Mysuru, South-Central Karnataka state, India. Email: vbkudachikar@cftri.res.in
\end{abstract}

\begin{abstract}
This study aims to develop and characterize the ready-to-serve beverage formulations from enzyme liquefied Kainth fruit pulp and to assess their stability during storage. Xanthan gum showed the highest acceptability in terms of stability (zeta potential $-29.10 \mathrm{mV}$ ) and sensory quality attributes, also carried out the effect of high-speed homogenization (20 MPa) on ready to serve beverages prepared with added xanthan gum. Both ready to serve beverage variations (with or without homogenization) showed high antioxidant potential (phenolics, flavonoids, and antioxidant activities) with better retention of vital nutrients (vitamins and minerals), organoleptically acceptable, microbiologically safe during storage, with shelf stability of these products up to four months at RT $\left(29 \pm 2^{\circ} \mathrm{C}\right)$ and five months at LT $\left(4 \pm 2^{\circ} \mathrm{C}\right)$ respectively. This study demonstrates that the product formulations from Kainth fruit have 4-6 months of shelf stability with a potential source of high phytonutrients and antioxidant properties that could promote and benefit human health.
\end{abstract}

\section{Keywords}

Kainth Fruit, Nutrients, Composition, Processed Products, Stability, Storage Conditions

\section{Introduction}

Kainth or Indian wild pear (Pyrus pashia Buch.-ham ex D. Don) is a less known and underutilized fruit species of the Rosaceae family, wildly grown in the Himalayan regions of India. Traditionally, it is used as a potential source of medications by tribal folks for economic growth and nutritional fulfilment [1]. The tree bears light brown-colored fruits at the matured ripe stage. The fully ripened fruit has a short shelf life of 3-4 days [2]. The fruit juice is astringent in taste and has diuretic properties. Locally, the ripe fruit is used for constipation treatment. As a home remedy, the fruit extract treats various health ailments (for eye problems, dyspepsia, headache, diaphoretic, hysteria, epilepsy, sore throat, irritability, anemia, stomach ache, and useful curing dysmenorrhea). Besides, fruit extract of the same species has shown medicinal value against dysentery [3]. The fruit is a rich source of biologically active compounds with therapeutic benefits and is traditionally used through decoctions, infusion, maceration, and percolations [4-5]. The decoction of dried fruits with other plant parts helps spleen and stomach function improvements. Micronutrient malnutrition or hidden hunger is a significant public health problem, especially in developing countries. Food-based approaches, especially dietary diversification to increase the consumption of locally available foods, could be a valuable source to fight against this hidden hunger [6]. 


\section{Methods}

\subsection{Fruit collection}

The fully matured Kainth fruits (60 kg) were procured from Tehri District, Uttarakhand (India), and immediately transported to the laboratory in corrugated fiber boxes. The fruits were washed, air-dried, deseeded, and packaged in low-density polyethylene (LDPE, 200 gauge-size) bags and stored at $-20^{\circ} \mathrm{C}$ (frozen storage) for further studies.

The thawed deseeded fruits (24.96 kg) homogenized (Model: JM60B, Serial No: 504031, JM Series Colloid Miller, Zhengzhou, China) with the addition of RO water (1:1). The pectinase enzyme treatment was given to homogenized pulp for better pulp yield [7]. Briefly, $0.5 \%$ of the pectinase enzyme was mixed with the homogenized pulp and incubated for four hours at $45 \pm 2^{\circ} \mathrm{C}$ with intermittent stirring. The treated pulp was filtered through a muslin cloth to get a fine juice, after the enzyme inactivation at $70 \pm 2^{\circ} \mathrm{C}$ for $5 \mathrm{~min}$. After cooling, the packed pulp (LDPE pouches, 200 gauge size) was stored at $-20^{\circ} \mathrm{C}$ till further use (see Figure 1 ).

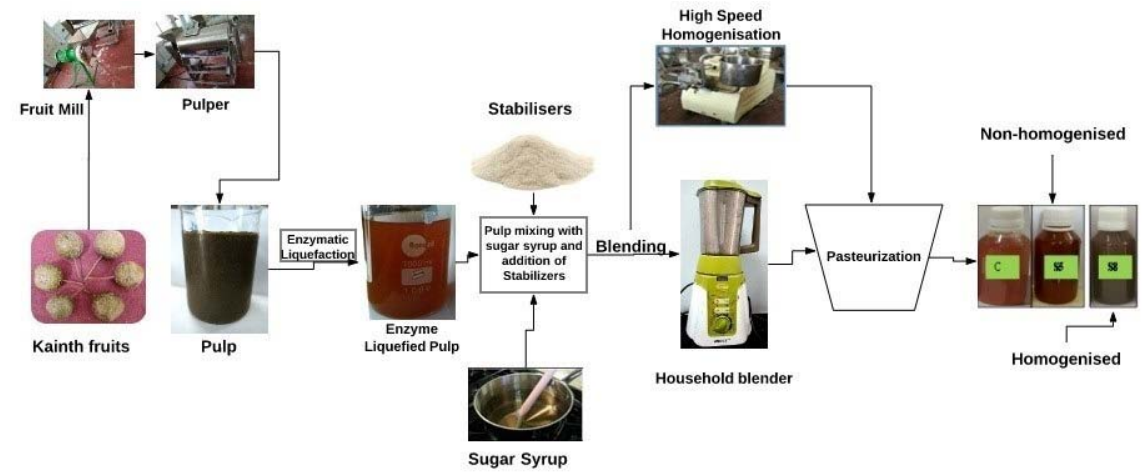

Figure 1. Flowchart showing the processing steps followed in beverage preparation.

\subsection{Beverage development and storage}

The enzyme liquefied pulp was used for the preparation of RTS beverages using various stabilizers. Briefly, sugar syrup and: the citric acid ratio was adjusted to $10{ }^{\circ}$ Brix and $0.3 \%$ acidity based on the percentage of total sugar and acidity present in fruit juice. Seven stabilizers [S1, S2-Pectin (low and high) methoxy content, S3-Sodium alginate, S4-Carbon methoxy cellulose (CMC), S5-Xanthan gum, S6-Tragacanth gum, and S7-Alginic acid] were used. Based on preliminary work, stabilizers were used at a concentration of $0.15 \%$ (Data not shown). The beverages were pasteurized at $90^{\circ} \mathrm{C}$ with a holding time of one minute, then cooled to $70 \pm 2^{\circ} \mathrm{C}$ and filled in pre-sterilized PET bottles. The best formulation was selected based on the efficacy of hydrocolloids in cloud stabilization. The sensory score also assessed the effect of high-speed homogenization (20 MPa) on the chosen formulation's physicochemical and rheological parameters. Eight formulations were prepared using seven stabilizers (S1-S7) and a variation of high-speed homogenization (S8). Storage studies were carried out at low $\left(\mathrm{LT} 4 \pm 2^{\circ} \mathrm{C}\right)$ and room (RT $29 \pm 2^{\circ} \mathrm{C}$ ) temperature along with a control (C) for the selected stabilizer and monitored various quality characteristics periodically.

\subsection{Physicochemical analysis for quality evaluation of beverages}

The total soluble solids (TSS) content of pulp and beverages was analyzed using a digital refractometer (Model: Atago RX-5000, Japan). The sample's pH was taken using a pH meter (Model: EUTECH Instruments-pH Tutor, Singapore). The total acidity was calculated [8]. The color of beverages was measured using a color measuring system (SHIMADZU, Model: UV 2100, Kyoto, Japan) with a wavelength range from 400 to $700 \mathrm{~nm}$. The results are expressed as L*, a*, and b* values. The sugar content was estimated as \% reducing Sugar and total Sugar as per the Lane and Eyon method [8].

\subsubsection{Quantitation of vitamin content}

The extraction and analysis of water-soluble (B1, B2, B3, B9) vitamins and fat-soluble (A, E) vitamins was done following the previously reported protocol with slight modifications [9]. The Shimadzu UPLC system used throughout this study consisted of a quaternary pump (20 AD), an auto-sampler (SIL-20AC HT), a degasser (DGU-20A5R), a column thermostat (CTO-20AC), a diode array detector (SPD-M20A), and a fluorescence detector (RF-20A). The LC solution data processor was used for controlling the whole liquid chromatographic system for evaluation and quantification using a reversed-phase- HPLC column (Thermo scientific C18; $250 \times 4.6 \mathrm{~mm}$, i.e., five $\mu \mathrm{m}$ ). The HPLC system's mobile phase consisted of solvent A (0.1 mol L-1 KH2PO4 at pH 7.0) and solvent B (methanol) for water-soluble vitamins. 
The analyses were carried out isocratically (90:10) at ambient temperature at a flow rate of $1.0 \mathrm{~mL}^{-1}{ }^{-1}$. The column eluate was monitored with a UV-Vis diode-array detector at $245 \mathrm{~nm}$ for thiamine hydrochloride, $268 \mathrm{~nm}$ for riboflavin, and folic acid, $260 \mathrm{~nm}$ for niacin. The identification of compounds was achieved by comparing their retention times with respective standards. The ascorbic acid (Vitamin C) was determined using the titrimetric method with a 2, 6-dichlorophenolindophenol reagent [8].

The fat-soluble vitamins were estimated using a gradient system with Mobile phase A (Water: THF; 95:5 with $0.05 \%$ acetic acid) and Mobile phase B (Acetonitrile: Methanol: THF; 75:25:5 with 0.035\% acetic acid). The gradient was as follows: At $0 \mathrm{~min}, 30 \% \mathrm{~B}$, at $3 \mathrm{~min} 30 \% \mathrm{~B}$, at $8 \mathrm{~min} 75 \% \mathrm{~B}$, at $15 \mathrm{~min} 100 \% \mathrm{~B}$, and $30 \mathrm{~min} 30 \% \mathrm{~B}$. The fat-soluble vitamins were identified and quantified with authentic standards (trans-retinol and $\alpha$-tocopherol) at ambient temperature.

\subsubsection{Total Phenolic content (TPC) and Total Flavonoid content (TFC)}

The total phenolic compound was estimated spectrophotometrically with Singleton and Rossi's modified Folin-Ciocalteau (FC) method [10]. The total flavonoid content in beverages was determined [11].

\subsubsection{Antioxidant activity determination}

The free radical scavenging activity of beverages prepared was determined using DPPH assay [12]. The ABTS assay was carried out as per the protocol of Nile and Park [13]. The Trolox was used as positive and deionized water as a negative control. The reading was taken precisely after $6 \mathrm{~min}$ of initial mixing at $734 \mathrm{~nm}$, and results presented as $\mathrm{mg}$ ascorbic acid and Trolox (TE) equivalent per $100 \mathrm{~mL}$ of beverages. According to Nile and Park's method, the Ferric reducing antioxidant power (FRAP) assay was carried out for the phenolic extracts of beverages [14].

\subsubsection{Minerals estimation}

The mineral content was analyzed by using Agilent 4210 Micro Plasma Atomic emission spectroscopy (MP-AES). The system had a One Neb Series 2 nebulizer, a double-pass glass cyclonic spray chamber, and an easy-fit torch. An AVS 4 four-port switching valve and SPS 4 auto sampler for sample injection. The AVS 4 is fully integrated with the 4210 MP-AES instrument hardware and controlled through the MP Expert software. The software continuously covers the wavelength and automatically adds the recommended wavelength, nebulizer flow rate, and External Gas Control Module (EGCM) setting for simplified method development to select the analysis elements and used Agilent calibration minerals mix (1, 2, and 5 ppm) to estimate the minerals (K, Na, P, Ca, Fe, Cu, Zn, and Mg).

\subsubsection{Particle Size Distribution/Viscosity determination}

The viscosity measured the consistency and quality of the beverages prepared. A rheometer (HAAKE RheoStress 6000 ) coupled with a thermostatic bath and a DC5 heating circulator was used to estimate viscosity. An inbuilt Peltier system controlled the temperature $\left(25^{\circ} \mathrm{C}\right)$ for analysis (TC 81$)$. The spindle with size- 20 was used to measure the viscosity of samples. The frequency sweeps in the range of $0.01-10 \mathrm{~Hz}$ within the linear viscoelastic region. The flow curves were collected in the CR (controlled rate) mode, from 0.1 to $250 \mathrm{~s}^{-1}$ during $250 \mathrm{~s}$. The software Rheowin 4.0 Data manager was used to obtain the rheological and statistical parameters.

\subsubsection{Zeta potential determination}

The zeta potential of prepared beverages with various stabilizers was estimated. The samples were loaded in transparent disposable zeta cuvettes, and their zeta potentials were determined using a zeta sizer (Zetasizer Nano ZS, Malvern Instruments Ltd, UK). The beverages were diluted to avoid multiple scattering effects. The data were recorded from at least 13 consecutive readings per sample with a time of equilibration of 60 seconds. All the measurements were done in triplicate.

\subsubsection{Determination of aroma molecules in Kainth beverages}

The signature aroma volatiles present in Kainth beverages were estimated using HS/SPME-GCMS technique as per Perestrelo et al. with modification [15]. Briefly, the beverage sample (5 mL) was mixed with sodium chloride $(0.5 \mathrm{~g})$ and placed in a $15 \mathrm{~mL}$ GC vial, and capped tightly. The vial was kept at $40{ }^{\circ} \mathrm{C}$ for $15 \mathrm{~min}$. The preconditioned fiber (50/30 $\mu \mathrm{m}$ CAR/DVB/PDMS) was inserted into the GC vial and further incubated for $30 \mathrm{~min}$ for adsorption of volatiles. Each sample was analyzed in triplicate along with blanks, not submitted to any extraction procedure. The fiber was injected into the heated injector port for desorption at $250^{\circ} \mathrm{C}$ for $5 \mathrm{~min}$ in split less mode.

The desorbed volatiles were analyzed using a Perkin Elmer gas chromatography equipped with a quadrupole mass spectrometer (Model: Turbomass Gold, Waltham, MA, USA) fitted with an Elite-1 fused silica column (N9316010, 30 $\mathrm{m} \times 0.25 \mathrm{~mm}$ x $0.25 \mu \mathrm{m}$ film thickness, Perkin Elmer) that was coated with polydimethylsiloxane. The carrier gas helium flow rate was set at $1 \mathrm{~mL} / \mathrm{min}$ and scanned from 40 to $400 \mathrm{Da}$ with a split ratio of 0:1. The oven temperature was maintained at $40^{\circ} \mathrm{C}$ for $2.5 \mathrm{~min}$ and then increased at $4^{\circ} \mathrm{C} / \mathrm{min}$ up to $250^{\circ} \mathrm{C}$. The injector port and detector temperatures were maintained at $250^{\circ} \mathrm{C}$, and the ionization voltage was $70 \mathrm{eV}$. Sample $(1 \mu \mathrm{L}$ diluted VO) was injected into the GC-MS system. The retention indices (RIs) were calculated for each compound against the n-alkanes standards $\left(\mathrm{C}_{8}-\mathrm{C}_{26}\right)$ 
using the Kovats method [16]. The volatile constituents were identified by comparing their GC RI with published literature [17]; the mass spectral fragmentation pattern was compared with the inbuilt library provided along with the instrument and the compound's published MS fragmentation pattern [18].

\subsection{Microbiological quality evaluation of beverages}

The product's microbiological quality (Total plate count, E.coli, and Staphylococcus sp.) was checked during storage at regular intervals using the standard pour plate method. One $\mathrm{mL}$ sample was pour plated and kept for incubation at ambient temperature for fungal growth and $37^{\circ} \mathrm{C}$ for plate count, E. coli, and Staphylococcus. The results were calculated as $\log _{10} \mathrm{cfu} / \mathrm{mL}$.

\subsection{Sensory quality evaluation of beverages}

Fifteen semi-trained panelists evaluated the samples for consumer acceptance. The acceptance testing was determined based on a 9-point hedonic scale ( 9 = like extremely and 1 = dislike extremely) for the attributes: appearance, color, odor, taste, texture, and overall acceptability.

\subsection{Statistical analyses}

All the experiments were done in triplicate and presented as mean \pm standard deviation (SD). The Data were subjected to analysis of variance (ANOVA) and Tuckey's multiple comparison tests using XLSTAT (2014.5.03) software. A probability of $5 \%$ or less is taken as a statistically significant variation.

\section{Results and discussion}

\subsection{Juice Yield and Standardization of suitable stabilizer for beverage formulation}

The enzymatic liquefaction by pectinase maximizes juice yield $(77.56 \pm 2.5 \%)$ compared to without liquefaction (56.1 $\pm 2.0 \%)$. The proximate analysis was carried out for juice (see Table 1 ).

Table 1. Proximate analysis of Kainth fine juice

\begin{tabular}{cc}
\hline Parameter & Value \\
\hline TSS ( ${ }^{\circ}$ Brix) & $10.40 \pm 0.25$ \\
pH & $3.54 \pm 0.09$ \\
Acidity & $0.74 \pm 0.15$ \\
Reducing Sugar & $5.12 \pm 0.29$ \\
Total sugar (\%) & $9.24 \pm 0.22$ \\
Protein (\%) & $1.59 \pm 0.15$ \\
Total Ash (\%) & $1.02 \pm 0.11$ \\
Minerals (mg/100gm) & \\
$\mathrm{K}$ & $234.98 \pm 14.47$ \\
$\mathrm{Mg}$ & $35.52 \pm 8.56$ \\
$\mathrm{Na}$ & $8.37 \pm 1.40$ \\
$\mathrm{Ca}$ & $7.78 \pm 0.55$ \\
$\mathrm{Mn}$ & $6.10 \pm 0.19$ \\
$\mathrm{Fe}$ & $3.92 \pm 0.11$ \\
$\mathrm{Zn}$ & $0.74 \pm 0.18$ \\
$\mathrm{Cu}$ & $0.65 \pm 0.0 .13$ \\
Vitamins ( $\boldsymbol{H g} / \mathbf{1 0 0 g})$ & $146.66 \pm 3.55$ \\
Vitamin A & $632.61 \pm 5.13$ \\
Vitamin E & $527.01 \pm 7.66$ \\
Vitamin B & $972.10 \pm 2.78$ \\
Vitamin B & $136.10 \pm 2.22$ \\
Vitamin B & \\
\hline
\end{tabular}

Note: values are the mean of 3 replications ( \pm standard deviations).

The RTS beverages were prepared using various stabilizers $(0.1-0.2 \%)$ and a concentration of $0.15 \%$. The best formulation was selected based on no visible sedimentation at the time of beverage preparation. The beverages prepared with xanthan gum (0.15\%) with and without homogenization showed less pulp sedimentation, high viscosity, and high zeta potential. They got high sensory acceptance in color, flavor, and texture, with an overall acceptability score of 8.55 
on the 9-point hedonic scale (see Table 2).

Table 2. Selection parameters for best ready to serve beverage product formulation

\begin{tabular}{|c|c|c|c|c|c|c|c|c|}
\hline \multirow[b]{2}{*}{ Formulation } & \multirow{2}{*}{$\begin{array}{l}\text { Viscosity } \\
\left(\mathrm{mPas}^{-1}\right)\end{array}$} & \multirow{2}{*}{$\begin{array}{c}\text { Zeta potential } \\
\text { (mV) }\end{array}$} & \multirow{2}{*}{$\begin{array}{l}\text { Particle size } \\
\quad(\mu \mathrm{m})\end{array}$} & \multirow{2}{*}{$\begin{array}{l}\text { \% Sedimenta- } \\
\text { tion }\end{array}$} & \multicolumn{4}{|c|}{ Sensory Evaluation } \\
\hline & & & & & Color & Flavor & Texture & $\begin{array}{c}\text { Overall } \\
\text { acceptability }\end{array}$ \\
\hline S1 & $2.82 \pm 0.14^{\mathrm{A}}$ & $-8.13 \pm 1.63^{\mathrm{B}}$ & $80.06 \pm 6.41^{\mathrm{BCD}}$ & $54.67 \pm 2.52^{\mathrm{CD}}$ & $6.9 \pm 0.28^{\mathrm{ABC}}$ & $7.14 \pm 0.72^{\mathrm{AB}}$ & $6.21 \pm 0.57^{\mathrm{A}}$ & $6.51 \pm 0.63^{\mathrm{A}}$ \\
\hline S2 & $4.23 \pm 0.64^{\mathrm{A}}$ & $-7.15 \pm 3.09^{\mathrm{B}}$ & $68.24 \pm 5.32^{\mathrm{BC}}$ & $66.67 \pm 1.53^{\mathrm{E}}$ & $6.8 \pm 0.28^{\mathrm{ABC}}$ & $6.9 \pm 0.32^{\mathrm{A}}$ & $6.32 \pm 0.57^{\mathrm{A}}$ & $6.59 \pm 0.66^{\mathrm{A}}$ \\
\hline S3 & $4.88 \pm 0.39^{\mathrm{A}}$ & $-9.74 \pm 3.56^{\mathrm{B}}$ & $61.07 \pm 5.92^{\mathrm{B}}$ & $73.50 \pm 1.73^{\mathrm{F}}$ & $7.2 \pm 0.28^{\mathrm{ABC}}$ & $6.85 \pm 0.55^{\mathrm{A}}$ & $6.64 \pm 0.67^{\mathrm{A}}$ & $7.00 \pm 0.54^{\mathrm{A}}$ \\
\hline S4 & $35.03 \pm 2.56^{\mathrm{B}}$ & $-29.10 \pm 3.79^{\mathrm{A}}$ & $64.28 \pm 7.50^{\mathrm{B}}$ & $\mathrm{NS}^{\mathrm{A}}$ & $8.05 \pm 0.72^{\mathrm{C}}$ & $8.5 \pm 0.59^{\mathrm{B}}$ & $8.5 \pm 0.71^{\mathrm{B}}$ & $8.55 \pm 0.27^{\mathrm{B}}$ \\
\hline S5 & $3.46 \pm 0.89^{\mathrm{A}}$ & $-4.49 \pm 2.47^{\mathrm{B}}$ & $95.40 \pm 12.20^{\mathrm{D}}$ & $59.33 \pm 1.15^{\mathrm{D}}$ & $6.68 \pm 0.64^{\mathrm{AB}}$ & $6.86 \pm 0.55^{\mathrm{A}}$ & $6.36 \pm 0.50^{\mathrm{A}}$ & $6.45 \pm 0.61^{\mathrm{A}}$ \\
\hline S6 & $2.48 \pm 0.37^{\mathrm{A}}$ & $-5.26 \pm 3.15^{\mathrm{B}}$ & $88.46 \pm 6.63^{\mathrm{D}}$ & $53.33 \pm 3.21^{\mathrm{C}}$ & $6.45 \pm 0.41^{\mathrm{A}}$ & $6.70 \pm 0.0 .47^{\mathrm{A}}$ & $6.7 \pm 0.57^{\mathrm{A}}$ & $6.8 \pm 0.47^{\mathrm{A}}$ \\
\hline S7 & $2.40 \pm 0.46^{\mathrm{A}}$ & $-2.35 \pm 1.14^{\mathrm{B}}$ & $85.22 \pm 6.42^{\mathrm{CD}}$ & $47.67 \pm 2.08^{\mathrm{B}}$ & $6.82 \pm 0.28 \mathrm{ABC}$ & $6.50 \pm 0.39^{\mathrm{A}}$ & $6.45 \pm 0.35^{\mathrm{A}}$ & $6.5 \pm 0.32^{\mathrm{A}}$ \\
\hline S8 & $32.56 \pm 2.89^{\mathrm{B}}$ & $-25.60 \pm 3.10^{\mathrm{A}}$ & $30.07 \pm 2.34^{\mathrm{A}}$ & $\mathrm{NS}^{\mathrm{A}}$ & $7.80 \pm 0.50^{\mathrm{BC}}$ & $7.15 \pm 0.80^{\mathrm{AB}}$ & $7.50 \pm 0.80^{\mathrm{AB}}$ & $7.6 \pm 0.40^{\mathrm{AB}}$ \\
\hline
\end{tabular}

Note: $(\mathrm{n}=3$; Mean \pm SD), values in rows and columns with different superscripts (A-F) have significant differences at $\mathrm{p}<0.05$ by Tukey (HSD) Test. Here, NS=No Sedimentation.

\subsection{Quality evaluation of the sensorial accepted beverages during storage}

The storage studies were carried out in terms of physicochemical and rheological changes in both non-homogenized beverages (code-S5) and homogenized beverages (code-S8) along with a control (without pulp) sample (code-C) at two storage conditions (see Table 3).

Table 3. Changes in the physicochemical, rheological and electrical property of Kainth fruit ready to serve beverages stored at ambient temperature (RT- $\left.29 \pm 2^{\circ} \mathrm{C}\right)$ and low temperature $\left(\mathrm{LT}-4 \pm 1^{\circ} \mathrm{C}\right)$ conditions

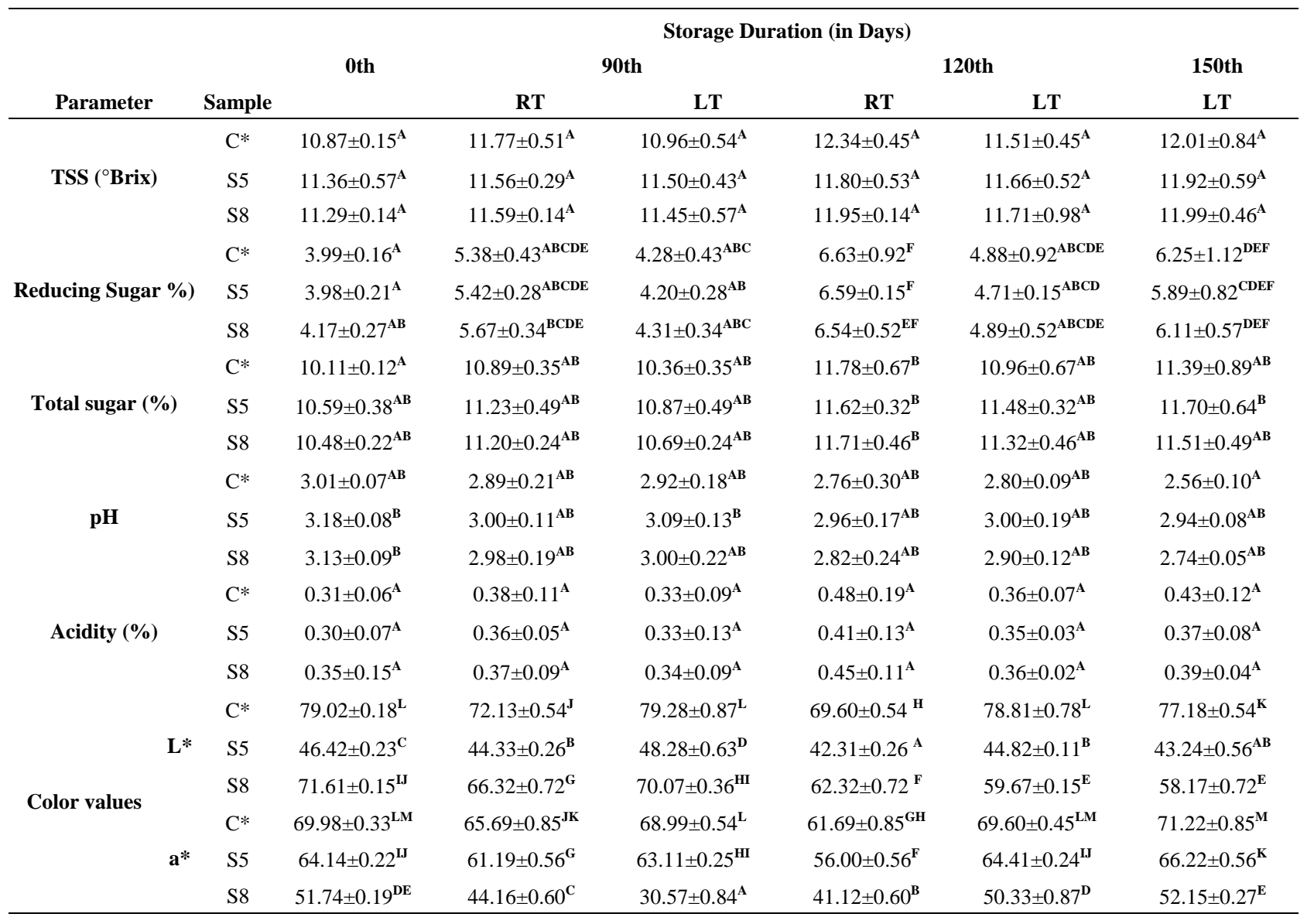




\begin{tabular}{cccccccc}
\hline & $\mathrm{C}^{*}$ & $15.62 \pm 0.27^{\mathrm{A}}$ & $14.58 \pm 0.42^{\mathrm{A}}$ & $15.55 \pm 0.64^{\mathrm{A}}$ & $13.28 \pm 0.42^{\mathrm{A}}$ & $15.01 \pm 0.55^{\mathrm{A}}$ & $15.32 \pm 0.11^{\mathrm{A}}$ \\
$\mathbf{b}^{*}$ & $\mathrm{~S} 5$ & $27.56 \pm 0.16^{\mathrm{A}}$ & $25.21 \pm 0.22^{\mathrm{A}}$ & $25.78 \pm 0.77^{\mathrm{A}}$ & $22.25 \pm 0.22^{\mathrm{A}}$ & $26.64 \pm 0.56^{\mathrm{A}}$ & $27.14 \pm 0.32^{\mathrm{A}}$ \\
& $\mathrm{S} 8$ & $12.24 \pm 0.11^{\mathrm{A}}$ & $11.17 \pm 0.61^{\mathrm{A}}$ & $9.64 \pm 0.18^{\mathrm{A}}$ & $10.41 \pm 0.61^{\mathrm{A}}$ & $14.08 \pm 0.59^{\mathrm{A}}$ & $14.98 \pm 0.61^{\mathrm{A}}$ \\
& $\mathrm{C}^{*}$ & $28.07 \pm 3.78^{\mathrm{ABCDE}}$ & $26.58 \pm 4.57^{\mathrm{ABC}}$ & $28.24 \pm 1.09^{\mathrm{ABCDE}}$ & $25.12 \pm 2.16^{\mathrm{B}}$ & $27.88 \pm 1.32 \mathrm{~B}^{\mathrm{BCDE}}$ & $26.78 \pm 1.39^{\mathrm{ABCD}}$ \\
Viscosity (mPas) & $\mathrm{S} 5$ & $35.03 \pm 4.01^{\mathrm{DE}}$ & $29.89 \pm 2.87^{\mathrm{ABCDE}}$ & $35.48 \pm 1.68^{\mathrm{E}}$ & $24.06 \pm 4.58^{\mathrm{A}}$ & $35.57 \pm 1.59^{\mathrm{E}}$ & $34.23 \pm 2.11^{\mathrm{CDE}}$ \\
& $\mathrm{S} 8$ & $32.56 \pm 0.25^{\mathrm{BCDE}}$ & $27.68 \pm 2.64^{\mathrm{ABCDE}}$ & $33.13 \pm 2.13^{\mathrm{BCDE}}$ & $23.45 \pm 3.87^{\mathrm{A}}$ & $33.59 \pm 2.24^{\mathrm{CDE}}$ & $29.58 \pm 1.99^{\mathrm{ABCDE}}$ \\
& $\mathrm{C}^{*}$ & $-31.8 \pm 0.29^{\mathrm{A}}$ & $-28.8 \pm 2.19^{\mathrm{AB}}$ & $-31.6 \pm 0.29^{\mathrm{A}}$ & $-23.8 \pm 3.39^{\mathrm{AB}}$ & $-31.4 \pm 1.27^{\mathrm{A}}$ & $-30.9 \pm 2.69^{\mathrm{A}}$ \\
Zeta potential (mV) & $\mathrm{S} 5$ & $-29.10 \pm 3.79^{\mathrm{AB}}$ & $-27.10 \pm 3.09^{\mathrm{AB}}$ & $-29.08 \pm 3.79^{\mathrm{AB}}$ & $-24.10 \pm 1.79^{\mathrm{AB}}$ & $-29.01 \pm 3.68^{\mathrm{AB}}$ & $-28.6 \pm 3.79^{\mathrm{AB}}$ \\
& $\mathrm{S} 8$ & $-25.60 \pm 3.10^{\mathrm{AB}}$ & $-23.60 \pm 3.70^{\mathrm{AB}}$ & $-25.60 \pm 3.10^{\mathrm{AB}}$ & $-20.60 \pm 2.10^{\mathrm{B}}$ & $-24.94 \pm 3.10^{\mathrm{AB}}$ & $-23.5 \pm 3.10^{\mathrm{AB}}$ \\
\hline
\end{tabular}

Notes: $(\mathrm{n}=3$; Mean $\pm \mathrm{SD})$, values in rows and columns with different superscripts $(\mathrm{A}-\mathrm{M})$ for each parameter have significant differences at $\mathrm{p}<0.05$ by Tukey (HSD) Test. L* indicates luminosity, $\mathrm{a}^{*}$ corresponds to greenness $(-) /$ redness $(+)$, and $\mathrm{b}^{*}$ corresponds to blueness $(-) /$ yellowness $(+)$.

Tuckey's HSD test for TSS showed no significant difference $(\mathrm{p} \geq 0.05)$ in RT and LT stored samples during storage, irrespective of the high-speed homogenization technique applied. TSS changes are mainly due to the hydrolysis of polysaccharides present [19]. No significant difference in TSS observed confirms beverages' stability up to four months at RT and five months at LT storage, respectively.

The acidity of freshly prepared S5, S8, and Control samples was $0.30 \%, 0.35 \%$, and $0.31 \%$, respectively. The increase in acidity was observed in all the samples but was non-significant ( $\mathrm{p} \geq 0.05$ ). It could be due to added preservatives, xanthan gum, and polyphenols present in beverages, which could have prevented the hydrolysis of polysaccharides and the high microbial growth enough to deteriorate the product.

The beverages prepared with xanthan gum showed a pleasing bright brown color. The higher opacity and bright tone due to xanthan can also be related to aggregates' formation, which promoted the scattered light [20]. The beverage samples showed a significant change $(\mathrm{p} \leq 0.05)$ in color values in RT and LT stored samples. In contrast, control samples showed no significant difference up to four months at LT condition. The sample S5 had a dark, intense brown color (Lower $\mathrm{L}^{*}$ values) than S8 and the control sample. The higher $\mathrm{L}^{*}$ values for the homogenized sample may be due to the high temperature achieved during high-speed homogenization, which caused decreased color intensity. These changes in color values, especially in RT stored samples, could also be due to melanoidins formation. The previous report showed a positive effect of storage temperature, mainly long-term fluctuation in temperature, oxidative and enzymatic degradation of pigments in clear pomegranate juice [21].

\subsection{Evaluation of vitamins content}

The beverages were evaluated for water-soluble (B1, B3, and C) and fat-soluble (A, E) vitamins. The beverages seemed to be a good source of vitamin A, E, B1, and B3 but low vitamin C sources (see Table 4).

Table 4. Physicochemical changes in Kainth fruit ready to serve beverages stored at ambient temperature $\left(\mathrm{RT}-29 \pm 2^{\circ} \mathrm{C}\right)$ and low temperature $\left(\mathrm{LT}-4 \pm 1^{\circ} \mathrm{C}\right)$ conditions

\begin{tabular}{|c|c|c|c|c|c|c|c|}
\hline \multirow[b]{3}{*}{ Parameter } & \multirow[b]{3}{*}{ Sample } & \multicolumn{6}{|c|}{ Storage Duration (in Days) } \\
\hline & & \multirow[t]{2}{*}{ 0th } & \multicolumn{2}{|c|}{ 90th } & \multicolumn{2}{|c|}{ 120th } & \multirow{2}{*}{$\begin{array}{l}\text { 150th } \\
\text { LT }\end{array}$} \\
\hline & & & RT & LT & RT & LT & \\
\hline Protein ( $\mu g$ & S5 & $233.36 \pm 2.39^{\mathrm{G}}$ & $218.36 \pm 3.19^{\mathrm{EF}}$ & $221.11 \pm 0.94^{\mathrm{EF}}$ & $206.69 \pm 3.16^{\mathrm{D}}$ & $214.51 \pm 3.70^{\mathrm{DE}}$ & $198.45 \pm 4.61^{\mathrm{C}}$ \\
\hline BSAE/100 mL) & S8 & $248.15 \pm 2.19^{\mathrm{H}}$ & $177.12 \pm 1.14^{\mathrm{B}}$ & $224.59 \pm 1.24^{\mathrm{F}}$ & $149.02 \pm 2.81^{\mathrm{A}}$ & $195.56 \pm 1.25^{\mathrm{C}}$ & $178.11 \pm 3.48^{\mathrm{B}}$ \\
\hline \multirow{2}{*}{$\begin{array}{c}\text { Total phenolic } \\
\text { (mg GAE/100 mL) }\end{array}$} & S5 & $141.48 \pm 0.68^{\mathrm{I}}$ & $98.46 \pm 1.53^{\mathrm{FG}}$ & $120.48 \pm 0.68^{\mathrm{H}}$ & $79.89 \pm 1.44^{\mathrm{C}}$ & $96.95 \pm 0.98^{\mathrm{F}}$ & $74.89 \pm 1.63^{\mathrm{B}}$ \\
\hline & S8 & $139.53 \pm 0.69^{\mathrm{I}}$ & $91.61 \pm 1.21^{\mathrm{E}}$ & $101.53 \pm 0.69^{G}$ & $76.58 \pm 2.11^{\mathrm{BC}}$ & $86.59 \pm 1.21^{\mathrm{D}}$ & $69.81 \pm 0.87^{\mathrm{A}}$ \\
\hline \multirow{2}{*}{$\begin{array}{l}\text { Total Flavonoid } \\
\text { (mg RE /100 mL) }\end{array}$} & S5 & $34.31 \pm 0.42^{\mathrm{H}}$ & $20.58 \pm 0.98^{\mathrm{CD}}$ & $31.18 \pm 2.41^{\mathrm{GH}}$ & $13.58 \pm 0.58^{\mathrm{AB}}$ & $27.98 \pm 0.68^{\mathrm{FG}}$ & $15.27 \pm 0.29^{\mathrm{AB}}$ \\
\hline & S8 & $32.03 \pm 0.57^{\mathrm{GH}}$ & $17.27 \pm 1.11^{\mathrm{BC}}$ & $27.01 \pm 3.12^{\mathrm{EF}}$ & $11.46 \pm 1.53^{\mathrm{A}}$ & $23.59 \pm 0.97^{\mathrm{DE}}$ & $15.31 \pm 0.71^{\mathrm{AB}}$ \\
\hline \multirow{2}{*}{$\begin{array}{c}\text { Vitamin A } \\
\text { (All trans-retinols- } \mu \mathrm{g})\end{array}$} & S5 & $29.97 \pm 1.78^{\mathrm{F}}$ & $27.11 \pm 0.98^{\mathrm{EF}}$ & $28.07 \pm 0.75^{\mathrm{EF}}$ & $26.07 \pm 0.75^{\mathrm{DE}}$ & $23.25 \pm 1.31^{\mathrm{BCD}}$ & $19.24 \pm 2.71^{\mathrm{A}}$ \\
\hline & S8 & $28.28 \pm 0.15^{\mathrm{EF}}$ & $24.87 \pm 0.67^{\mathrm{CDE}}$ & $26.30 \pm 0.50^{\mathrm{DEF}}$ & $21.30 \pm 0.50^{\mathrm{ABC}}$ & $19.56 \pm 0.78^{\mathrm{AB}}$ & $17.58 \pm 1.88^{\mathrm{A}}$ \\
\hline \multirow{2}{*}{ Vitamin E ( $\mu \mathrm{g})$} & S5 & $35.32 \pm 0.89^{\mathrm{J}}$ & $29.56 \pm 0.89^{\mathrm{H}}$ & $29.73 \pm 0.21^{\mathrm{H}}$ & $24.63 \pm 0.21^{\mathrm{EF}}$ & $25.67 \pm 0.46^{\mathrm{FG}}$ & $19.20 \pm 0.26^{\mathrm{C}}$ \\
\hline & S8 & $32.61 \pm 0.94^{\mathrm{I}}$ & $23.12 \pm 0.94^{\mathrm{DE}}$ & $26.86 \pm 0.86^{\mathrm{G}}$ & $11.96 \pm 0.86^{\mathrm{A}}$ & $21.17 \pm 0.25^{\mathrm{D}}$ & $17.03 \pm 0.21^{\mathrm{B}}$ \\
\hline \multirow{2}{*}{ Vitamin $B_{1}(\mu g)$} & S5 & $55.50 \pm 0.44^{\mathrm{I}}$ & $41.22 \pm 0.28^{\mathrm{F}}$ & $48.83 \pm 1.12^{\mathrm{G}}$ & $27.13 \pm 1.12^{\mathrm{B}}$ & $41.53 \pm 0.31^{\mathrm{F}}$ & $29.10 \pm 0.70^{\mathrm{C}}$ \\
\hline & S8 & $52.10 \pm 0.85^{\mathrm{H}}$ & $38.44 \pm 0.84^{\mathrm{E}}$ & $40.92 \pm 0.91^{\mathrm{F}}$ & $23.80 \pm 0.30^{\mathrm{A}}$ & $33.53 \pm 1.59^{\mathrm{D}}$ & $27.94 \pm 0.65^{\mathrm{BC}}$ \\
\hline \multirow{2}{*}{ Vitamin $B_{3}(\mu g)$} & S5 & $170.83 \pm 1.92^{\mathrm{H}}$ & $122.25 \pm 0.56^{\mathrm{E}}$ & $147.15 \pm 4.71^{\mathrm{G}}$ & $86.15 \pm 1.71^{\mathrm{C}}$ & $137.50 \pm 1.00^{\mathrm{F}}$ & $85.16 \pm 2.84^{\mathrm{C}}$ \\
\hline & S8 & $166.56 \pm 1.28^{\mathrm{H}}$ & $118.42 \pm 0.93^{\mathrm{E}}$ & $141.11 \pm 3.69^{\mathrm{F}}$ & $67.00 \pm 1.52^{\mathrm{A}}$ & $111.33 \pm 4.67^{\mathrm{D}}$ & $75.77 \pm 1.18^{\text {B }}$ \\
\hline \multirow{2}{*}{ Vitamin C (mg) } & S5 & $8.55 \pm 0.11^{\mathrm{H}}$ & $5.32 \pm 0.29^{\mathrm{G}}$ & $4.22 \pm 0.21^{\mathrm{F}}$ & $2.36 \pm 0.21^{\mathrm{BC}}$ & $3.22 \pm 0.89^{\mathrm{DE}}$ & $1.72 \pm 0.78^{\mathrm{AB}}$ \\
\hline & S8 & $8.69 \pm 0.31^{\mathrm{H}}$ & $3.91 \pm 0.24^{\mathrm{EF}}$ & $4.00 \pm 0.17^{\mathrm{F}}$ & $2.11 \pm 0.17^{\mathrm{ABC}}$ & $2.71 \pm 0.28^{\mathrm{CD}}$ & $1.48 \pm 0.40^{\mathrm{A}}$ \\
\hline
\end{tabular}

Note: $(n=3$; Mean \pm SD), values in rows and columns with different superscripts $(A-J)$ for each parameter have signficant differences at $\mathrm{p}<0.05$ by Tukey (HSD) Test. 
The sample S5 had a higher content of Vitamin A (29.97 $\mu$ ATRE/100 mL), Vitamin E (35.32 $\mu \mathrm{g} / 100 \mathrm{~mL})$, Vitamin B1 $(55.50 \mu \mathrm{g} / 100 \mathrm{~mL})$, and Vitamin B3 $(170.83 \mu \mathrm{g} / 100 \mathrm{~mL})$. The vitamin content in both beverages showed significant $(\mathrm{p} \leq 0.05)$ losses during the storage. The LT stored samples showed higher retention of vitamins irrespective of the homogenization effect. The RT sample's vitamin losses could be due to fluctuation in $\mathrm{pH}$, temperature, and reducing agents present in a beverage like metal ions [22]. The S5 showed higher vitamin content throughout the storage study, which could be due to low microbial growth and less oxidation activity due to more antioxidant content than the S8 sample. Vitamin B9 was also analyzed but was not detectable due to its instability at the low $\mathrm{pH}$ of beverages and oxidation during processing [23].

\subsection{Total phenolics and flavonoid content}

Phenolics play an essential role in body functions and have health-promoting properties. Apart from health benefits, phenolics and flavonoids played a crucial role in processed product quality in terms of flavor and taste as phenolics contribute to its astringent nature [24]. The storage study showed no significant $(\mathrm{p} \leq 0.05)$ changes in total phenolics among the beverages S5 and S8. Nevertheless, there was a gradual but significant decrease in phenolic content in both S5 and S8 samples during the storage study at both temperatures. The RT samples showed lower phenolic content when compared to LT samples up to four months of storage. The S5 had higher retention of total phenolic (141.48 to 79.89 $\mathrm{mg} \mathrm{GAE} / 100 \mathrm{~mL}$ ) at RT up to four months and $74.89 \mathrm{mg}$ GAE/100 mL at LT storage for up to five months. A similar trend was observed for total flavonoids. The lower phenolic and flavonoid content in S8 might be due to the high temperature developed during homogenization and high microbial growth. The decrease in antioxidants value could also be due to the oxidation of polymeric compounds in beverages. The results showed that low-temperature storage was better to prevent the losses of total phenolics and total flavonoid content in beverages during long-term storage [19].

\subsection{Evaluation of antioxidant activities}

The Kainth beverage contained bioactive compounds like phenolics, flavonoids, and citric acid with potent antioxidant activities. The antioxidant activities of beverages were examined using DPPH, ABTS, and FRAP assay (Supplementary Table I). Both the beverages S5 and S8 showed high antioxidant potential. The DPPH and FRAP activity revealed a slight but significant $(\mathrm{p} \leq 0.05)$ decrease in antioxidant potential for both $\mathrm{S} 5$ and S8 samples during storage. The ABTS assay showed no significant $(\mathrm{p} \geq 0.05)$ changes in both samples. The LT-stored samples retained better antioxidant potential when compared to RT-stored samples. A previous study showed a similar retention pattern in antioxidant potential during high-speed homogenization and pasteurization of mulberry juice [25]. A related study demonstrated that the antioxidant capacity in cloudy and clear juices of strawberries decreased by less than $10 \%$ at $4^{\circ} \mathrm{C}$ [26]. However, when the same samples were stored at $25^{\circ} \mathrm{C}$, the results showed an almost double reduction in antioxidant capacity.

The decrease in antioxidant potential could be correlated with the corresponding reduction of phenolic compounds. The overall results showed that both the beverages S5 and S8 have excellent antioxidant and nutraceutical potential. The study also revealed that high-speed homogenization of $20 \mathrm{MPa}$ does not affect the antioxidant potential of beverages.

\subsection{Evaluation of minerals}

The mineral content in the beverages showed that the beverages are a good source (see Figure 2).
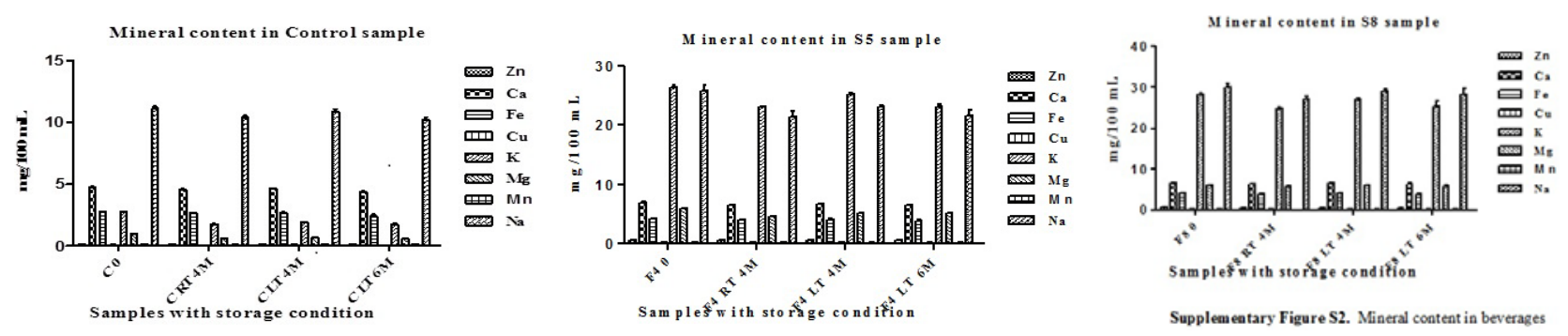

Figure 2. Mineral content in beverages (Control sample; S5 sample; S8 sample).

The S8 also had high sodium content $(30.15 \mathrm{mg} / 100 \mathrm{~mL})$. There was a slight difference in calcium content in S5 (6.9 $\mathrm{mg} / 100 \mathrm{~mL}$ ) and S8 $(6.65 \mathrm{mg} / 100 \mathrm{~mL})$ samples. Minor changes were found in all the estimated minerals during the storage study. The LT samples showed excellent retention in mineral content than RT stored samples, which might be due to the low microbial growth and fewer oxidation changes at low temperatures. 


\subsection{Evaluation of particle size}

The average particle size of non-homogenized beverages $(64.28 \mu \mathrm{m})$ was nearly double compared with the homogenized one $(30.07 \mu \mathrm{m})$ (see Figure 3).

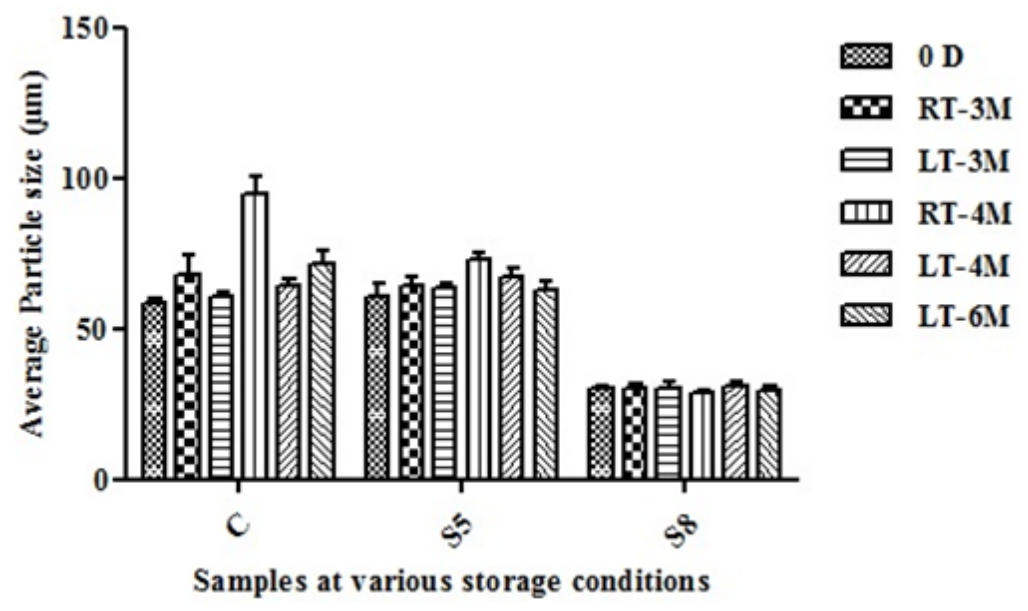

Figure 3. Particle size analysis of beverages (Control sample; S5 sample; S8 sample).

The samples S5 and S8 were found stable. A slight increase in particle size was observed at a low temperature. On the other hand, beverages S5 and control samples stored at ambient temperature showed little growth in particle size up to three months and increased significantly $(\mathrm{p} \leq 0.05)$ at the end of the four-month. The S8 sample showed a decrease in particle size (30.07 to $28.67 \mu \mathrm{m}$ ), which could be due to the breakdown of polysaccharides by microbial degradation and oxidation during the later stages of the storage study.

The beverages showed better stability over the entire storage period due to the protective effect of hydrocolloid used. Smaller average particle size, along with xanthan gum could help better the distribution of pulp particles and prevent coalescence of pulp particles [27]. Previous reports also showed that a pressure of $40 \mathrm{MPa}$ produced the mulberry juice of an average particle size of $27.90 \mu \mathrm{m}$. Furthermore, increased pressure showed losses of phenolics and other vital nutrients and particle size reduction [25, 28]. Hence, $20 \mathrm{MPa}$ pressure is satisfactory for stabilizing beverages, retaining nutrients and antioxidants.

\subsection{Evaluation of rheological property (viscosity)}

The main stabilizing action of food hydrocolloids is via viscosity modification in the continuous aqueous phase. Xanthan gum is a branched hydrocolloid and can form many hydrogen bonds and thus significantly increases the viscosity. Thus, S5 showed the highest viscosity at a concentration of $0.15 \%$ and was found the most stable (Table 3 ). While the high-speed homogenization reduced the consistency of beverages prepared with xanthan gum, it thus showed lower viscosity. The storage study showed slight but significant $(\mathrm{p} \leq 0.05)$ viscosity changes in $\mathrm{S} 5$, S8, and Control at both the storage conditions. A previous report showed that increased storage time could decrease beverage viscosity [29].

\subsection{Evaluation of electrical property (zeta potential)}

The suspension with a high zeta potential is self-stable as electrostatic repulsion between similarly charged colloidal particles inhibits coalescence and enhances stability [30]. The beverages prepared with xanthan gum showed the highest zeta potential among all stabilizers used (Table 3). The zeta potential of S5 $(-29.10 \mathrm{mV})$ was found higher when compared to S8 $(-25.60 \mathrm{mV})$. The low zeta potential in S8 could be due to the denaturation of pulp proteins and colloidal particles' aggregation by high-speed homogenization [31]. The control sample showed the highest zeta potential, which could be due to no pulp particles interfering with the stabilizer used. During the storage study, the samples S5, S8, and Control (C) showed high stability and marginal changes observed in zeta potential for up to four months at RT and five months at LT conditions. These retentions might be due to the xanthan gum used, which provided a high surface/charge ratio.

\subsection{Volatile compounds present in Kainth beverages}

The aroma volatiles present in Kainth beverages was estimated to identify the signature aroma molecules. The results 
on the distribution of chemical groups present in Kainth beverages showed that esters (69.4\%) and aliphatic alkanes (12.8\%) were present as predominant chemical groups (Table 6). Hexyl acetate, methyl hexanoate, and 2, 4, 4-Trimethyl-3-(2-methyl propanoyloxy) pentyl] 2-methyl propanoate were the abundant esters identified in beverages prepared using xanthan gum. A previous report by [15] also showed hexyl acetate as the predominant volatile compound responsible for fruity flavor in red fruits, pear, and apple juices irrespective of the type of juice using the HS-SPME/GC-MS technique (Table 5).

Table 5. Volatiles compound in fresh S5 beverages using GC-MS

\begin{tabular}{ccccc}
\hline Peak no. & RT & Compound name & KI & \% GC Area \\
\hline 1 & 6.89 & p-Xylene & 878.01 & 4.57 \\
2 & 8.05 & Methyl hexanoate & 911.64 & 18.59 \\
3 & 10.42 & 1-Methyl-4-ethylbenzene & 979.19 & 2.17 \\
4 & 10.75 & Ethyl hexanoate & 987.32 & 2.55 \\
5 & 11.26 & Hexyl acetate & 999.42 & 20.91 \\
6 & 11.92 & D-Limonene & $1,019.11$ & 2.58 \\
7 & 13.49 & Ether, hexyl pentyl & $1,062.60$ & 5.32 \\
8 & 13.68 & 3,4-Dimethyl-Decane & $1,067.64$ & 3.56 \\
9 & 14.40 & Nonanal & $1,085.68$ & 2.09 \\
10 & 14.46 & 2-Methyl-1,5-heptadien-4-ol & $1,087.02$ & 2.15 \\
11 & 14.97 & 2,6-Dimethylnonane & $1,099.20$ & 1.63 \\
12 & 15.10 & 4,7-Dimethylundecane & $1,102.96$ & 2.54 \\
13 & 15.33 & Methyl 6-methyl heptanoate & $1,110.13$ & 1.95 \\
14 & 18.56 & 6-Ethyl-2-methyldecane & $1,198.63$ & 2.81 \\
15 & 21.42 & Oxalic acid, isohexyl neopentyl ester & $1,283.05$ & 2.23 \\
16 & 25.23 & 6-Ethyl-2-methyldecane & $1,398.16$ & 3.87 \\
17 & 26.51 & 2,6-Di-tert-butyl-1,4-benzoquinone & $1,441.16$ & 2.68 \\
18 & 30.57 & 2,4,4-Trimethyl-3-(2-methyl propanoyloxy)pentyl] 2-methyl propanoate & $1,576.79$ & 17.81 \\
\hline & & & & \\
& & &
\end{tabular}

Table 6. Compound category in fresh S5 beverages using GC-MS

\begin{tabular}{ccc}
\hline S.No & Compound category & \% GC Area \\
\hline 1 & Aldehydes & 2.09 \\
2 & Alcohols & 2.15 \\
3 & Aliphatic alkanes & $\mathbf{1 2 . 7 8}$ \\
4 & Aromatic alkene & 6.74 \\
5 & Esters & $\mathbf{6 9 . 3 6}$ \\
6 & Ketones & 4.31 \\
7 & Monoterpenes & 2.58 \\
\hline
\end{tabular}


Table S1. Various antioxidant activities and changes in antioxidant potential in Kainth fruit processed RTS beverages stored at ambient temperature (RT- $\left.29 \pm 2{ }^{\circ} \mathrm{C}\right)$; low temperature $\left(\mathrm{LT}-4 \pm 1^{\circ} \mathrm{C}\right)$ conditions

\begin{tabular}{|c|c|c|c|c|c|}
\hline \multirow[b]{3}{*}{ Parameter } & \multirow[b]{3}{*}{ Sample } & \multicolumn{4}{|c|}{ Storage Duration (in Days) } \\
\hline & & \multirow[t]{2}{*}{ 0th } & \multicolumn{2}{|c|}{ 120th } & \multirow{2}{*}{$\begin{array}{c}\text { 150th } \\
\text { LT }\end{array}$} \\
\hline & & & RT & $\mathbf{L T}$ & \\
\hline \multirow{2}{*}{ DPPH (mg AAE/100 mL) } & S5 & $30.98 \pm 1.23^{\mathbf{E}}$ & $24.26 \pm 0.27^{\mathrm{A}}$ & $29.54 \pm 0.25^{\mathrm{DE}}$ & $25.26 \pm 0.27^{\mathrm{AB}}$ \\
\hline & S8 & $27.04 \pm 0.53^{\mathrm{BC}}$ & $25.51 \pm 0.17^{\mathrm{AB}}$ & $26.91 \pm 1.44^{\mathrm{BC}}$ & $24.06 \pm 0.82^{\mathrm{A}}$ \\
\hline \multirow{2}{*}{ DPPH (mg BHTE/100 mL) } & S5 & $33.21 \pm 1.16^{\mathbf{D}}$ & $26.73 \pm 0.52^{\mathbf{A}}$ & $29.11 \pm 1.26^{\mathrm{ABC}}$ & $27.79 \pm 0.30^{\mathbf{A B}}$ \\
\hline & S8 & $31.06 \pm 2.35^{\mathrm{BCD}}$ & $30.55 \pm 1.36^{\mathbf{B C D}}$ & $30.84 \pm 0.23^{\mathrm{CD}}$ & $26.85 \pm 0.23^{\mathrm{A}}$ \\
\hline \multirow{2}{*}{ ABTS (mg AAE/100 mL) } & S5 & $26.71 \pm 6.58^{\mathbf{A}}$ & $19.44 \pm 2.99^{\mathbf{A}}$ & $24.84 \pm 3.54^{\mathrm{A}}$ & $19.65 \pm 5.99^{\mathbf{A}}$ \\
\hline & S8 & $23.93 \pm 5.81^{\mathbf{A}}$ & $21.19 \pm 3.43^{\mathrm{A}}$ & $22.04 \pm 2.53^{\mathrm{A}}$ & $21.61 \pm 3.77^{\mathrm{A}}$ \\
\hline \multirow{2}{*}{ ABTS (mg TE/100 mL) } & S5 & $27.05 \pm 6.31^{\mathbf{A}}$ & $19.06 \pm 4.62^{\mathrm{A}}$ & $21.58 \pm 2.26^{\mathbf{A}}$ & $18.29 \pm 2.92^{\mathbf{A}}$ \\
\hline & S8 & $26.13 \pm 6.10^{\mathbf{A}}$ & $20.89 \pm 7.19^{\mathbf{A}}$ & $24.05 \pm 4.47^{\mathrm{A}}$ & $20.84 \pm 2.87^{\mathrm{A}}$ \\
\hline \multirow{2}{*}{ FRAP (mg AAE/100 mL) } & S5 & $113.65 \pm 6.36^{\mathbf{B C}}$ & $88.66 \pm 1.72^{\mathrm{ABC}}$ & $109.52 \pm 0.66^{\mathrm{BC}}$ & $75.29 \pm 4.19^{\mathrm{A}}$ \\
\hline & S8 & $116.08 \pm 3.64^{\mathrm{C}}$ & $87.97 \pm 4.15^{\mathrm{ABC}}$ & $114.25 \pm 3.51^{\mathrm{BC}}$ & $78.31 \pm 5.41^{\mathrm{A}}$ \\
\hline \multirow{2}{*}{ FRAP (mg FE/100 mL) } & S5 & $73.71 \pm 1.64^{\mathrm{BC}}$ & $63.62 \pm 2.40^{\mathrm{ABC}}$ & $67.59 \pm 2.30^{\mathrm{ABC}}$ & $63.90 \pm 0.29^{\mathrm{ABC}}$ \\
\hline & S8 & $74.07 \pm 2.23^{\mathrm{C}}$ & $63.04 \pm 6.86^{\mathrm{ABC}}$ & $71.71 \pm 7.23^{\mathrm{ABC}}$ & $61.08 \pm 2.99^{\mathrm{A}}$ \\
\hline
\end{tabular}

Notes: ( $\mathrm{n}=3$; Mean \pm SD), values in rows and columns with different superscripts (A-E) for each parameter have significant differences at $\mathrm{p}<0.05$ by Tukey (HSD) Test.

\subsection{Microbiological quality evaluation}

Despite the high-water activity of fruit beverages, low $\mathrm{pH}$ reduces microorganism growth in RTS beverages. The freshly prepared Kainth beverages showed no growth of the microorganism (Figure 4). During storage, the control samples showed highest total plate count $\left(1.45 \log _{10} \mathrm{cfu} / \mathrm{mL}\right)$ followed by S8 $\left(1.10 \log _{10} \mathrm{cfu} / \mathrm{mL}\right)$ and S5 $\left(0.95 \log _{10}\right.$ $\mathrm{cfu} / \mathrm{mL}$ ). The LT stored samples showed no growth for up to three months. Bacterial growth in both RT and LT samples was found within the permissible limit of FSSAI [32]. The lower bacterial growth in our study could be due to lower $\mathrm{pH}$ comparatively. The Staphylococcus aureus, E.coli, Yeast, and Moulds were absent. Hence, beverages are safe to consume up to four months at RT and five months at LT storage.

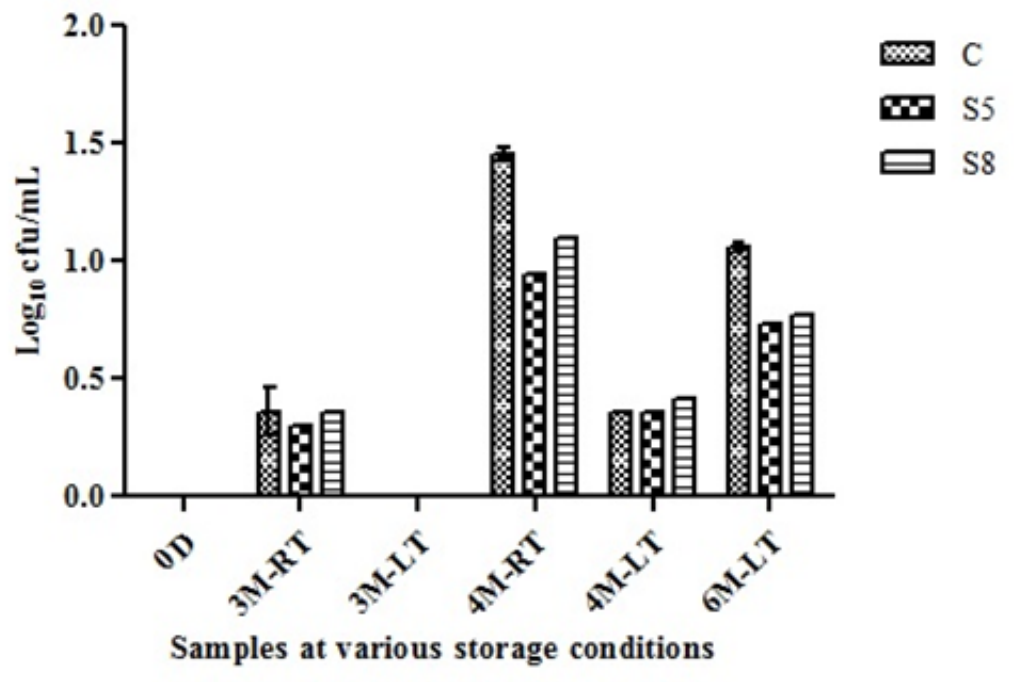

Figure 4. Microbial analysis of beverages (Control sample; S5 sample; S8 sample): Total Plate count during the storage period. 


\subsection{Sensory quality evaluation}

Figure 5 illustrates the results of sensory profile based on mean values of quality attributes (Color, flavor texture, Sweetness, Sourness, and Overall quality) of samples C, S5, and S8 at RT $\left(29 \pm 2^{\circ} \mathrm{C}\right)$ and $\mathrm{LT}\left(4 \pm 2^{\circ} \mathrm{C}\right)$ storage conditions for four and five months respectively.

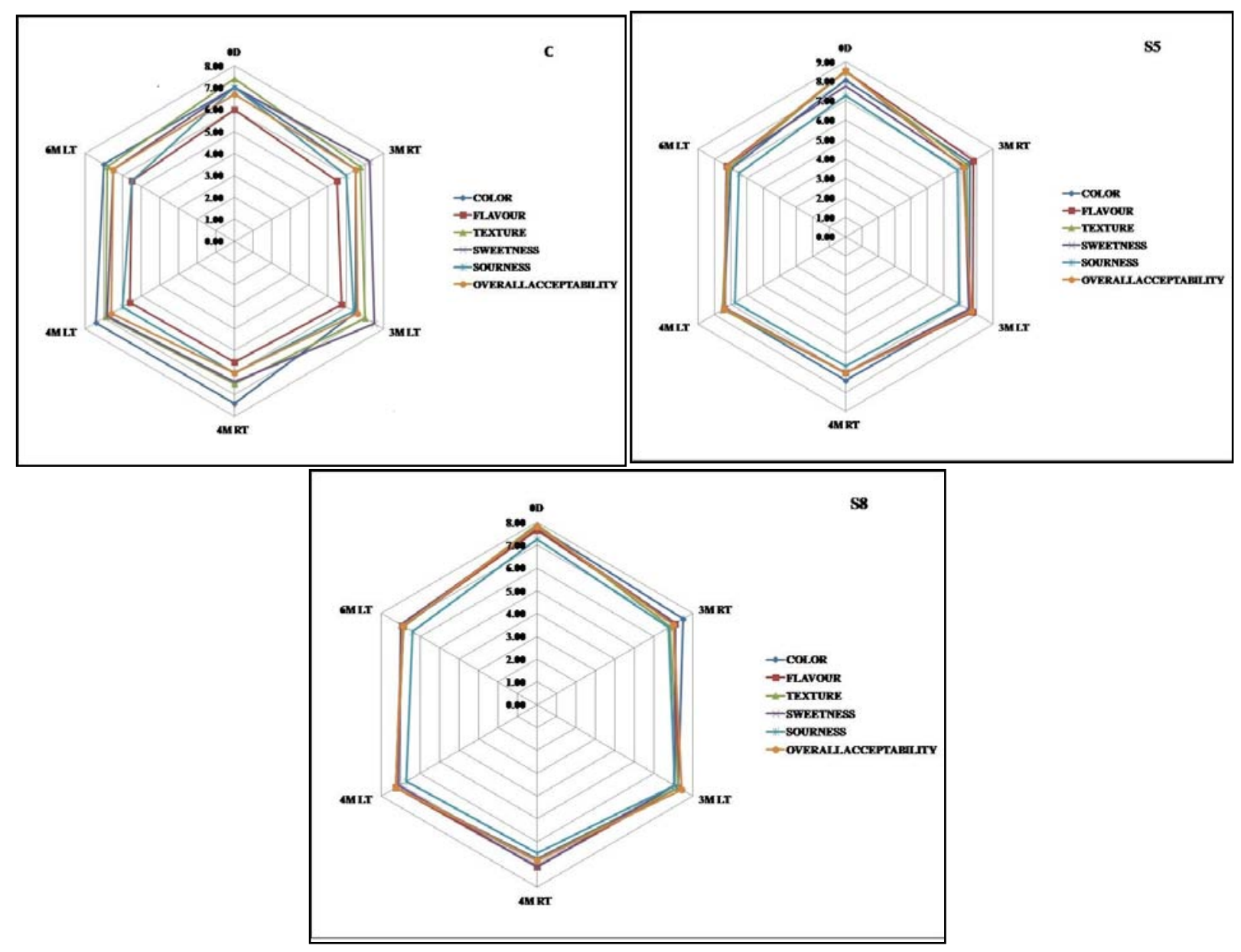

Figure 5. Sensory analysis of beverages (Control sample; S5 sample; S8 sample) during storage study.

The prepared beverages S5 and S8 got an average overall acceptability score of 8.55 and 7.80, respectively, while the control sample got 6.7 ratings from the panellists. During the storage studies, the S5 was the most acceptable product at both temperature conditions, followed by the S8 sample. The S5 had a bright brown color and was very much liked by the panellists. In contrast, homogenized S8 had a little light brown color, which we have already discussed, due to the high-temperature gain during high-speed homogenization. The other significant changes observed were texture, sourness, color, and flavor in RT stored samples than LT stored samples.

\section{Conclusion}

The results showed that the type of stabilizer affects the rheological stability significantly. Xanthan gum had provided the highest stability to Kainth beverages at $0.15 \%$ irrespective of high-speed homogenization. The beverages (S5 and S8) were stable and a good source of fat-soluble and water-soluble vitamins, rich in minerals and bioactive compounds, and showed high antioxidant potential. Hence, xanthan gum is suitable for thermal processing and the rheological stability of Kainth beverages.

\section{Acknowledgments}

The authors are grateful to Dr. Sridevi Annapurna Singh, Director of CSIRcentral Food Technological Research I nstitute, Mysuru, India, for her keen interest and constant encouragement regarding the present study. 


\section{Disclosure statement}

The authors declare that they have no financial conflict of interest or personal relationship that could have influenced the work reported in this paper.

\section{Funding}

The authors are grateful to CSIR, New Delhi, for providing economic support in this research project under Major Lab Project (MLP0235).

\section{References}

[1] Ahmad, Z. (2007). Country report on plant genetic resources for food and agriculture. Pakistan Agricultural Research Council, Islamabad, Pakistan.

[2] Parmar, C. and Kaushal, M. K. (1982). Pyrus Pashia. In: Wild Fruits. India: Kalyani Publishers, New Delhi, pp. 78-80.

[3] Chettri, N., Sharma, E., and Lama, S. D. (2005). The non-timber forest produces utilization, distribution, and status in a trekking corridor of Sikkim, India. Lyonia, 8, 89-100.

[4] Siddiqui, S. Z., Ali, S., Rehman, A. U., Rubab, K., Abbasi, M. A., Ajaib, M., and Rasool, Z. G. (2015). Pyrus pashia, A persuasive source of natural antioxidants. Pakistan J Pharm Sci., 28, 1763-1772.

[5] Murad, W., Ahmed, A., Gilani, S. A., and Khan, M. A. (2011). Indigenous knowledge and folk use of medicinal plants by the tribal communities of Hazar Nao Forest, Malak, and District, North Pakistan. J Med Plants Res., 5, 1072-1086.

[6] Adebayo-Oyetoro, A. O., Ogundipe, O. O., Adeyemo, I. G., Ogundipe, F. O., Bamidele, F. A., and Adeyeye, S. A. O. (2016). Chemical, sensory, and shelf life study of pawpaw juice-milk blend. Cog Food Agri., 2, 1271-1276.

[7] Chauhan, A. S., Gul Afroze, S., Ramesh, M. N., Yadav, A. R., Rekha, M. N., and Ramteke, R. S. (2004). Optimization of papaya's enzymatic liquefaction (Carica papaya L.) and jackfruit (Artocarpus heterophyllus Lam.) pulp using response surface methodology. Food Agri Environ, 2, 108-113.

[8] Ranganna, S. (1999) Handbook of analysis and quality control for fruits and vegetable products. 3rd Edition, Tata McGraw-Hill Publishing Co Ltd, New Delhi., India.

[9] Sami, R., Li, Y., Qi, B., Wang, S., Zhang, Q., Han, F., Ma, Y., Jing, J., and Jiang, L. (2014). HPLC Analysis of Water-Soluble Vitamins (B2, B3, B6, B12, and C) and Fat-Soluble Vitamins (E, K, D, A, and $\beta$-Carotene) of Okra (Abelmoschus esculentus). J Chem., 2014, 1-6. https://doi.org/10.1155/2014/831357.

[10] Singleton, V. L. and Rossi, J. A. (1965). Colorimetry of total phenolics with phosphomolybdic phosphotungstic acid reagents. American J Enol Viticulture, 16, 144-158.

[11] Aadil, R. M., Zeng, X. A., Han, Z., and Sun, D. W. (2013). Effects of ultrasound treatments on quality of grapefruit juice. Food Chem., 141, 3201-3206.

[12] Wang, X., Beckhman, T.H., Morris, J.C., Chen, F., and Gangemi, J. D. (2008). Bioactivities of gossypol, 6-methoxygossypol, and 6, 6'-dimethoxygossypol. J Agri Food Chem., 56, 4393-4398.

[13] Nile, S. H. and Park, S. W. (2014). HPTLC analysis antioxidant, anti-inflammatory, and antiproliferative activities of Arisaema tortuosum tuber extract. Pharm Biol, 52, 221-227.

[14] Nile, S. H. and Park, S. W. (2014). Antioxidant: a-glucosidase and xanthine oxidase inhibitory activity of bioactive compounds from maize (Zea mays L.). Chem Biol Drug Des., 83, 119-125.

[15] Perestrelo, R., Silva, C., Silva, P., Medina, S. and Câmara, J. S. (2019). Differentiation of fresh and processed fruit juices using volatile composition. Molecules, 24, 974.

[16] Jennings, W. and Shibamoto, T. (1980). Qualitative Analysis of Flavor and Fragrance Volatiles by Gas Capillary Chromatography. USA: Academic Press, New York, 248-250.

[17] Anonymous. (2020). www.wildflavors.com/EMEA-EN/company/about-us.

[18] Adams, R. P. (2001). Identification of Essential Oil Components by Gas Chromatography/Quadrupole Mass Spectroscopy. Allured Publishing Corp, Carol Stream, IL, USA.

[19] Hemalatha, R., Kumar, A., Prakash, O., Supriya, A., Chauhan, A. S., and Kudachikar, V. B. (2018). Development and quality evaluation of ready-to-serve (RTS) beverage from Cape gooseberry (PhysalisperuvianaL.). Beverages, 4, 42.

[20] Bryant, C. M. and McClements, D. J. (2000). Optimizing preparation conditions for heat-denatured whey protein solutions to be used as cold-gelling ingredients. J Food Sci., 65, 259-263.

[21] Oziyci, H. R., Karhan, M., Tetik, N., and Turhan, I. (2012). Effects of processing method and storage temperature on clear 
pomegranate juice turbidity and color. J Food Process Pres., 37, 899-906.

[22] Ottaway, P. B. (2019). Fortification of beverages with vitamins and minerals. In: Functional and specialty beverage technology, $1^{\text {st }}$ Edition. CRC Press, Washington, DC., USA, 71-91.

[23] Paine-Wilson, B. and Chen, T. S. (1979). Thermal destruction of folacin, the effect of pH and buffer ions. J Food Sci., 44, 717-722.

[24] Sharma, M., Gehlot, R., Singh, R., and Siddiqui, S. (2012). Changes in chemical constituents and overall acceptability of guava Jamun blend RTS drink and squash during storage. Beverage Food World, 39, 39-42.

[25] Yu, Y., Xu, Y., Wu, J., Xiao, G., Fu, M., and Zhang, Y. (2014). Effect of ultra-high pressure homogenization processing on phenolic compounds, antioxidant capacity and anti-glucosidase of mulberry juice. Food Chem., 153, 114-120.

[26] Cao, X., Bi, X., Huang, W., Wu, J., Hu, X., and Liao, X. (2012). Changes of quality of high hydrostatic pressure processed cloudy and clear strawberry juices during storage. Innov Food Sci Emerg Technol., 16, 181-190.

[27] Pettitt, D. J., Wayne, J. E. B., Nantz, J. J. R., and Shoemaker, C. F. (1995). Rheological Properties of Solutions and Emulsions Stabilized with Xanthan Gum and Propylene Glycol Alginate. J Food Sci., 60, 528-531.

[28] Zhou, L., Guan, Y., Bi, J., Liu, X., Yi, J., Chen, Q., Wu, X., and Zhou, M. (2017). Change of the rheological properties of mango juice by high-pressure homogenization. LWT-Food Sci Tech, 82, 121-130.

[29] Pang born, R. M., Gibbs, Z. M., and Tassan, C. (1978). Effect of hydrocolloids on apparent viscosity and sensory properties of selected beverages. $J$ texture stud., 9, 415-436.

[30] Morrison, I. D. and Ross, S. (2012). Colloidal Dispersions. 6th Edition, APA, Wiley-Inter science, New York., USA.

[31] Yu, Z. Y., Jiang, S. W., Cao, X. M., Jiang, S. T., and Pan, L. J. (2016). Effect of high-pressure homogenization (HPH) on the physical properties of taro (Colocasia esculenta L). Schott) pulp. J Food Eng, 177, 1-8.

[32] Food Safety and Standards Authority of India. (2017). Standards for Non-Carbonated water-based beverages (Non-alcoholic) (Ref. No: Stds / SP (Water and Beverages). FDA Bhawan, Kotla Road, New Delhi, India. 